\title{
Structural Details of Dictyosomal Pores ${ }^{1}$
}

\author{
Werner W. Franke and Ulrich Scheer \\ Department of Cell Biology, Institute of Biology II, \\ University of Freiburg i. Br., Germany
}

Received December 29, 1971

\begin{abstract}
Structural details of the dictyosomal pores in several plant cell types are described from tangential and cross sections of Golgi cisternae. Frequency distributions of the sizes of such Golgi pores are given and compared with the corresponding values of nuclear pores in the same cells. Golgi pore inner diameters are less homogeneously distributed and can be as small as $100 \AA$ or less. They are not simply cisternal holes, but are often associated with centrally located electron dense granules or rods and with inner pore filaments. This organization, which is very common in dictyosomal pores in plant and animal cells, has some similarities with the structural architecture of nuclear envelope and annulate lamellar pore complexes. The particulate material associated with the dictyosomal pores shows spatial and structural relationship to cytoplasmic ribosomes. Possible modes of Golgi pore formation and some consequences of these observations for interpretation of nuclear pore structures are discussed.
\end{abstract}

The occurrence of "fenestrae" or "pores" within cisternae of dictyosomes and endoplasmic reticulum (ER) is a structural feature with which every electron microscopist is familiar. Such "pores" are clearly distinguished from the classic "pore complexes" of the nuclear envelope and the annulate lamellae by the absence of the characteristic nonmembranous structures of the pore complexes, for instance, the annular components (for reviews see, e.g., 5, 12, 15, 25, 28). No detailed study, however, has so far dealt with the ultrastructure of the cisternal pores in dictyosomes and ER.

\section{MATERIALS AND METHODS}

Pollen tubes of Lilium longiflorum and Clivia miniata grown on the surface of a $10 \%$ sucrose solution with $10 \mathrm{ppm}$ of boric acid, were fixed with glutaraldehyde and osmium tetroxide according to the previously described procedures (7). Cultures of Haplopappus gracilis were grown and fixed in a similar fashion (10). Root tips and stem sections of onion (Allium cepa) and cress seedlings (Lepidium sativum) were fixed as described elsewhere (5). Embedding and sectioning procedures used can also be seen from these previous articles. Micrographs were taken with a Siemens Elmiskop IA or 101.

${ }^{1}$ The work was supported by the Deutsche Forschungsgemeinschaft, Germany. 


\section{RESULTS}

In all plant cell types studied, the cisternae of the forming (proximal) face of the dictyosomes were characterized by frequent fenestrae (e.g., Fig. 1). Only very occasionally were such fenestrae encountered with more distal cisternae of the Golgi apparatus (Figs. 4 and 5). A conspicuous feature of the forming face in the pollen tube material was its close and consistent association with a distinct "free" (i.e., nonmembrane bound) polysome (dictyosome-associated polysome, $d P$ in Figs. 1-6). Closer inspection of the fenestrae, however, revealed that they were not just "holes" filled with the cytoplasmic groundsubstance but contained distinct substructural components within them. The most prominent among these was central electron opaque material which appeared in cross section most frequently as a thin, up to $500 \AA$ long, rodlike element (Figs. 1 and 5). Often this central rod in the Golgi fenestrae seemed to be associated with the ribosomes of the dictyosomal polysome on its proximal end (e.g., Figs. 1 and 5). In other situations the central element was more suggestive of a granular structure (Figs. 4 and 5).

Figures $2-5$ show configurations that may be interpreted as representing stages in the formation of such pores. At certain sites the two membranes constituting a cisterna protruded toward each other and could come into local contact (Figs. 2 and 3). This obviously can occur multiply and simultaneously within one cisterna, with a more or less regular spacing between the fusion sites (e.g., Fig. 2). A later stage in pore formation might be represented by the situation seen in Fig. 4: in the course of a membrane rearrangement, a hole was produced at such fusion sites the margins of which very often showed direct strandlike connections with the ribosomes of the dictyosome-associated polysome (Figs. 4 and 5). The majority of the pores were larger than $250 \AA$ in diameter. However, at higher magnification a class of very small pores with diameters of $150 \AA$ and below was seen (Figs. 4 and 6). The typical trilaminar membrane substructure can be traced along the margin of such "minipores" (Fig. 6) and clearly shows their true porous nature.

A corresponding view was obtained from sections tangential to dictyosomal cisternae. Figure 7 shows sections grazing a No. 2 cisterna, determined from a section series (cisternae are counted from proximal to distal face, according to the mode indicated in Fig. 1) in the lower part and a No. 3 cisterna in the upper part. The more proximal cisternae were recognized by numerous fenestrae, particularly in its periphery, whereas such fenestrae are less frequent the more distal one proceeds in the direction of the dictyosomal axis. Again the very center of such pores was marked by a ca. 100-200 $\AA$ thick electron dense element which bears strong resemblance to the descriptions of the so-called "central granules" in the pores of the nuclear envelope and the annulate lamellae (e.g., 5, 12, 16, 22). This similarity with 
nuclear pores goes even further in that the central granules sometimes were seen connected with the pore circumference by thin filaments (Figs. 7 and 8). In No. 1 Golgi cisternae (e.g., Fig. 8), which very often were so porous that they represented a network rather than a cisternal sac, the pores were often very large and the central element here showed a strong similarity in size and contrast to the ribosomes in the cytoplasm nearby (Fig. 8). The pores were not always strictly circular but often displayed somewhat more ellipsoidal or irregular outlines, in particular in the most proximal cisternae.

"Minipores" were also identified in tangential section (Fig. 9), where their diameter could be measured with a relatively high precision. When dictyosomal pore sizes were compared with luminal widths of the nuclear pore complexes in the very same cell type, one obtained a distribution shown, for example, in the case of Haplopappus tissue culture cells in Fig. 10: nuclear pore complexes are different by being generally larger and more homogeneous in distribution of size frequency.

Other interesting structures that were repeatedly observed in the course of the present study were (a) the inter- and intracisternal rods and crosslink elements recently described (Figs. 1-6) $(8,20)$, and (b) membranous bridge profiles which span the cisternal lumen (e.g., Fig. 6).

\section{DISCUSSION}

The above description of the substructure of the porous interruptions in cisternal sacs of dictyosomes contains two findings which are especially relevant to our understanding of cytomembranes.

A. The sizes of the dictyosomal pores are variable. However, the existence of truly membrane-surrounded pores of $150 \AA$ and less inner diameter is a novel observation and is especially noteworthy since the existence of such small "minipores" in general had been excluded on theoretical grounds relating to the molecular architecture of

FIG. 1. Cross section through a dictyosome in freshly germinated Clivia pollen tube. Numbers indicate the position of the cisterna within the stack, counted from forming to maturing face. Pairs of arrows denote typical dictyosomal pores containing centrally located electron dense elements of rodlike shape. At the lower pair of arrows such a central rod appears to be associated with a ribosome of the dictyosome-associated polysome $(d P)$. $\times 230000$.

FIGs. 2-5. Details of dictyosomal pores in cross sections of dictyosomes of the Lilium pollen tube. Sites of local contact of the two cisternal membranes are recognized in Fig. 2, where they appear somewhat regularly spaced in cisterna No. 1 (arrowheads) as well as in the corresponding cisterna in Fig. 3. Strandlike connections with the ribosomal particles of the dictyosome-associated polysomes are seen at the cisternal pores marked by the pairs of arrows in Figs. 4 and 5. A central pore element is denoted by the arrow in the lower right of Fig. 4. A "minipore" can be identified in cisterna No. 3 in Fig. 4 (arrow at upper right). All, $\times 200000$.

FIG. 6. Lilium pollen tube dictyosomes in cross section showing a clearly delineated "minipore" (arrow). As is clearly seen in inset, the membrane structure is continuous around the pore margin (denoted by the small arrows). Note also the intracisternal membrane crosspiece between the arrowheads (see inset). $\times 196000$; inset, $\times 370000$. 


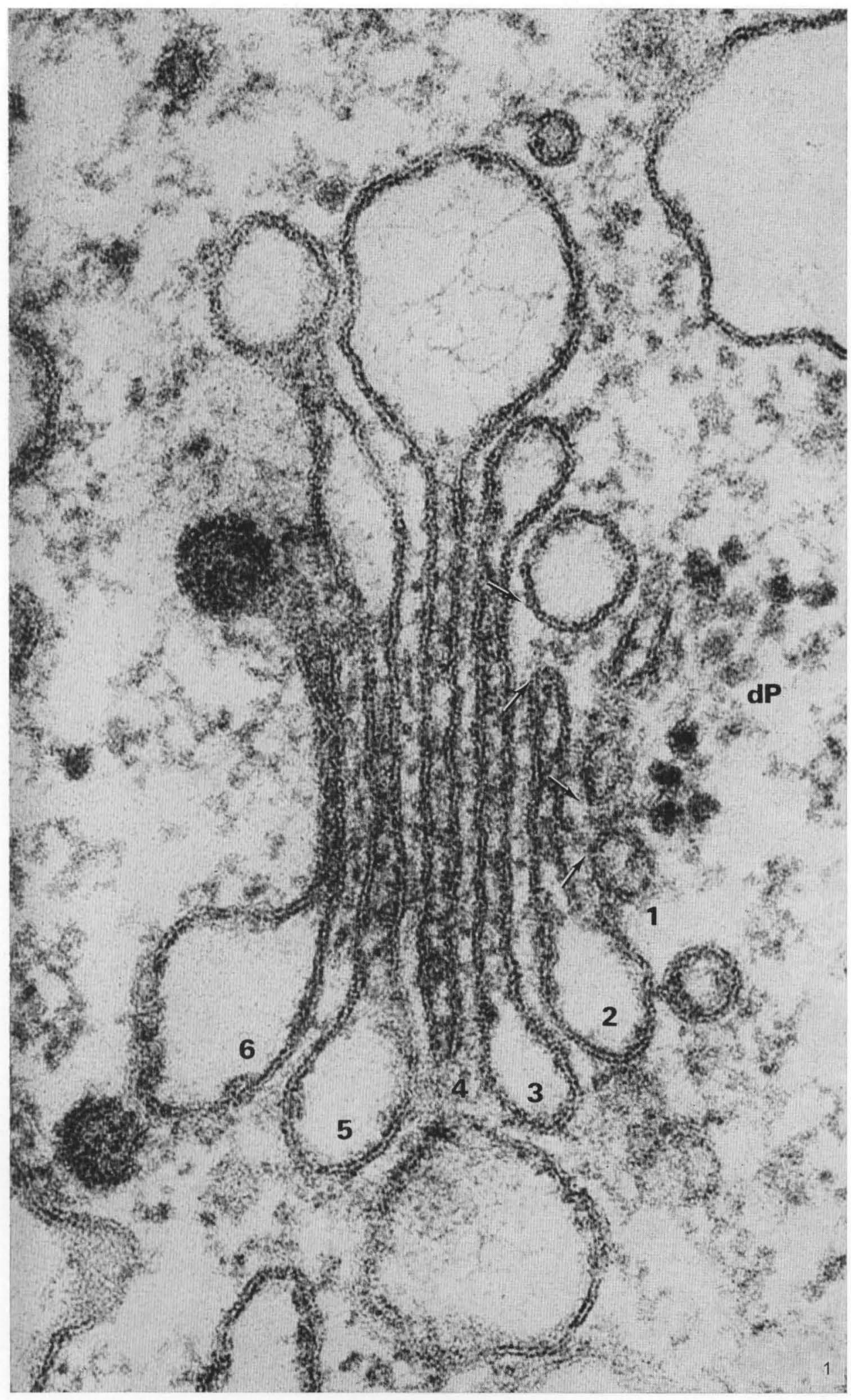



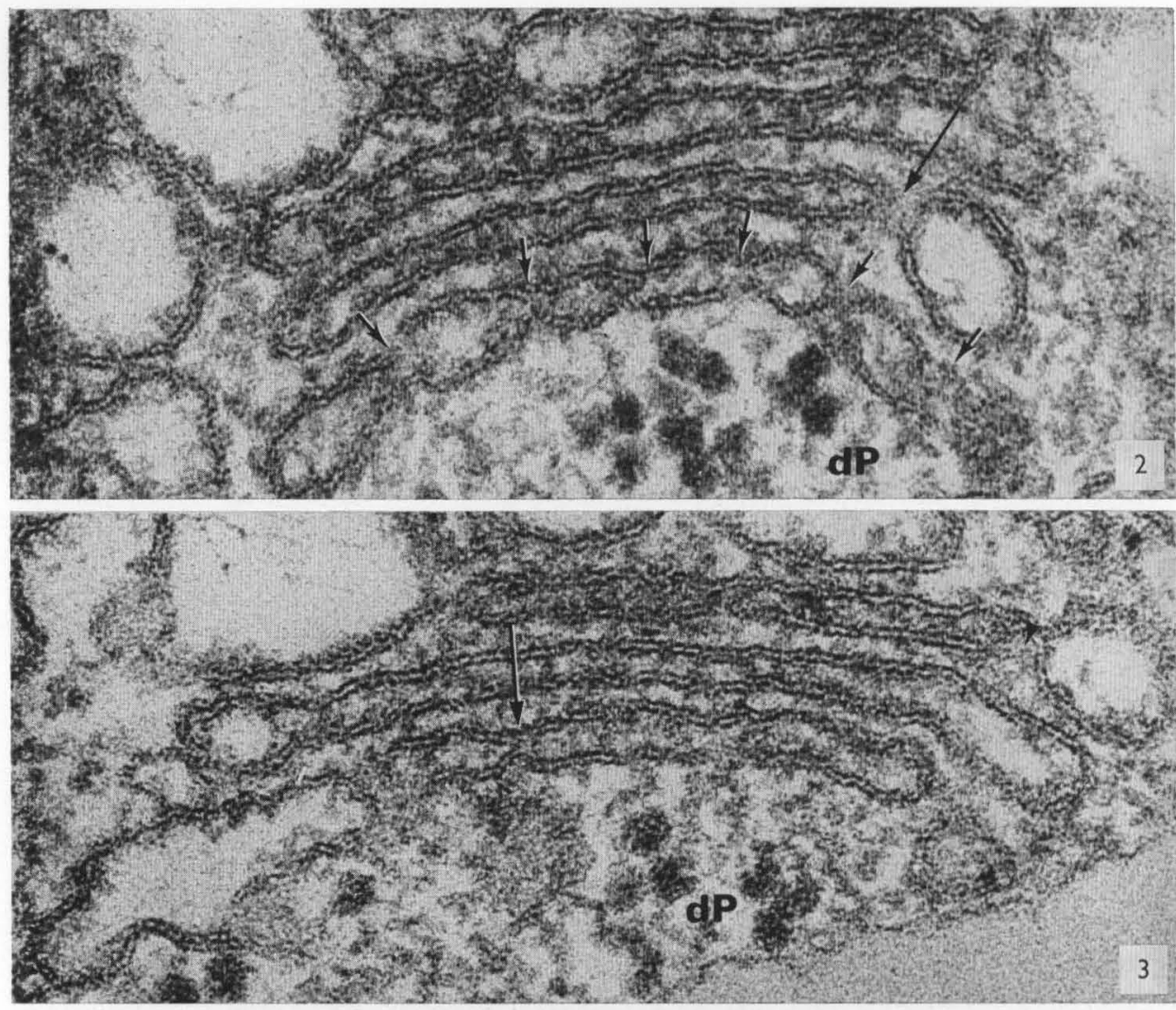

7. 2 l.

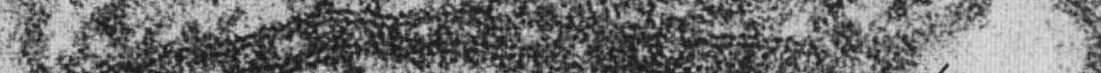

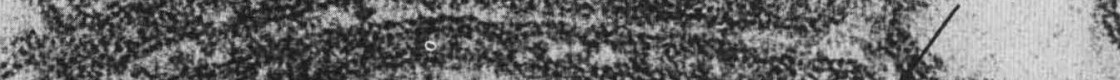

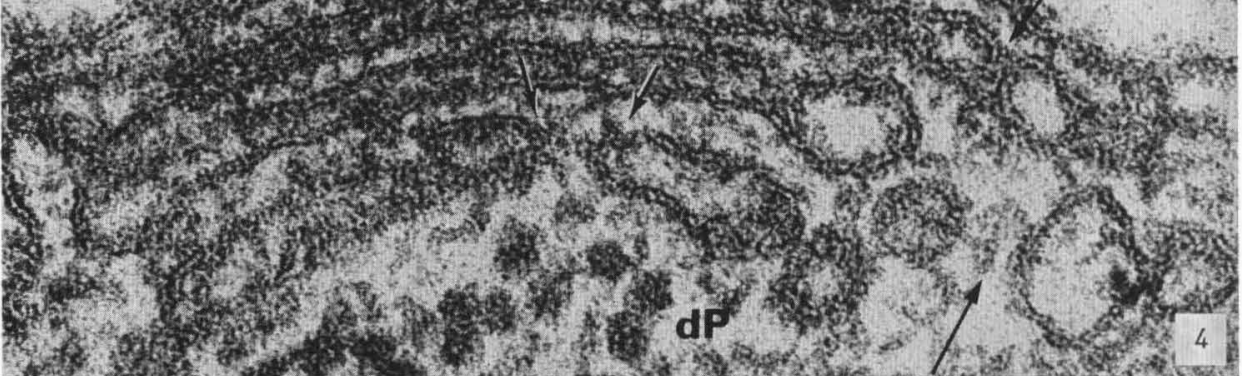

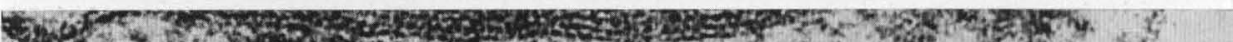

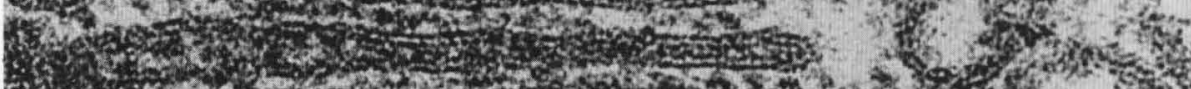

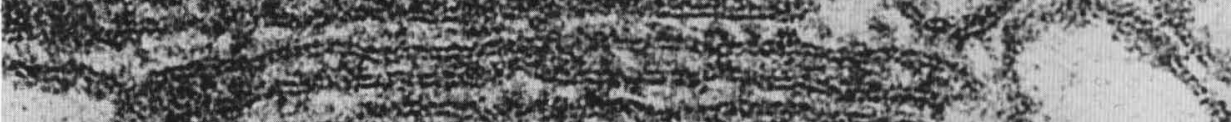

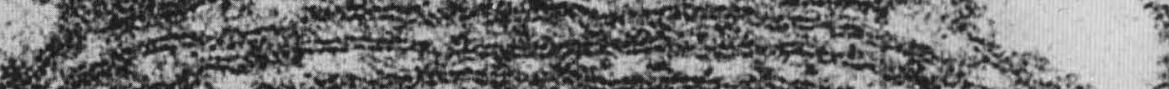
40 of

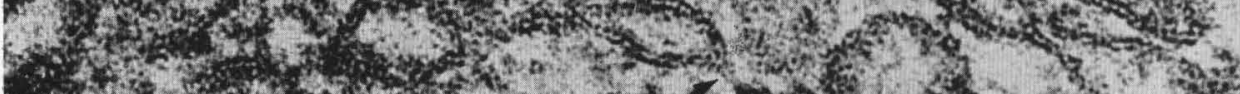

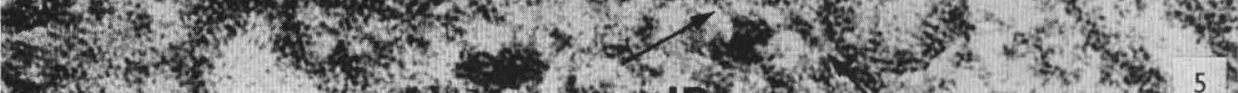

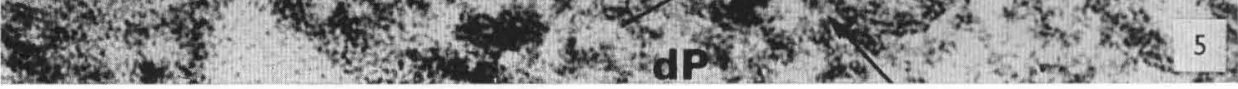



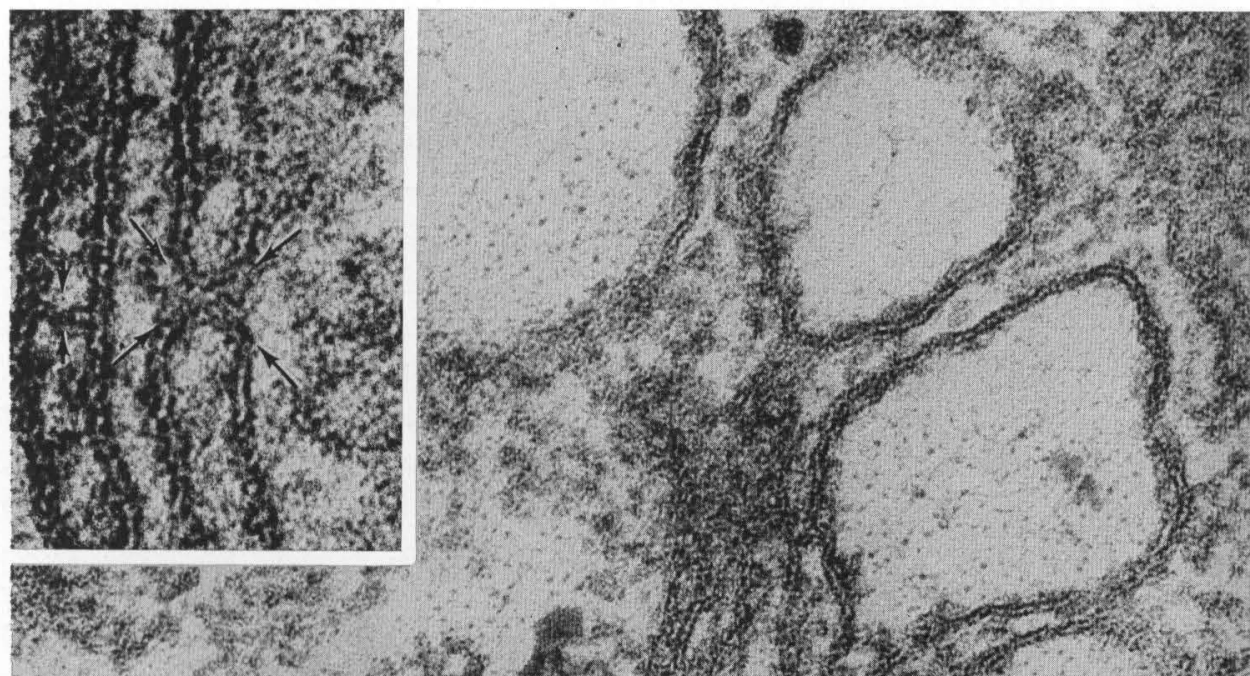

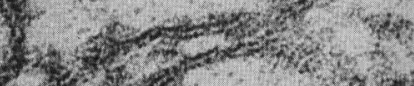

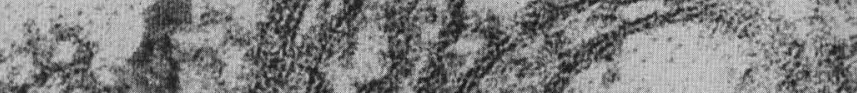

(a) 6.5.

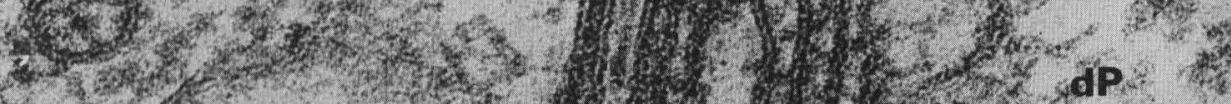

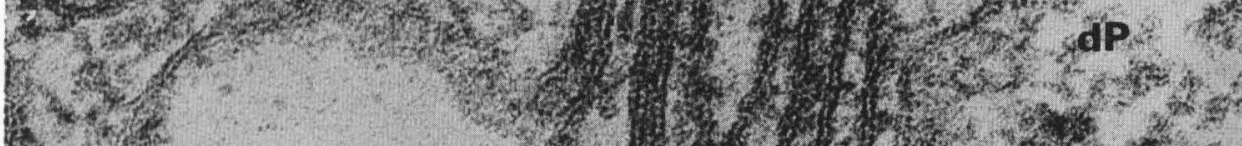

is set $x$

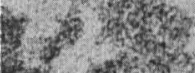

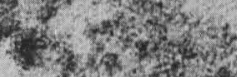

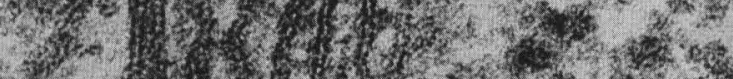

4.

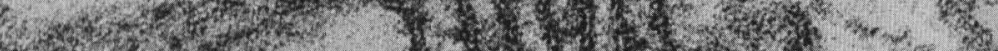

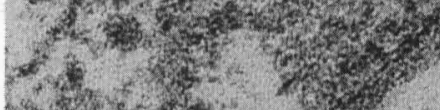

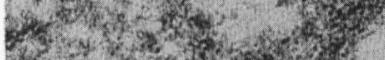

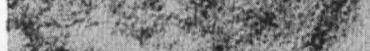

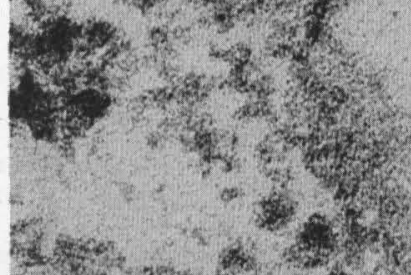

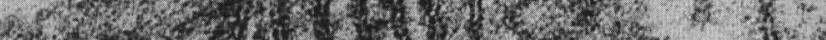

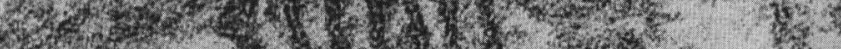

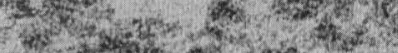

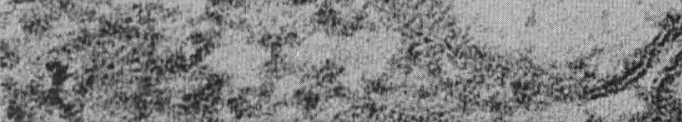

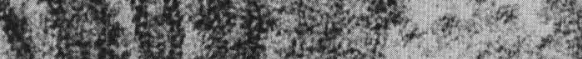

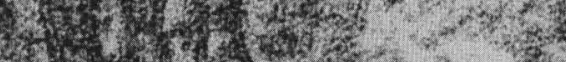

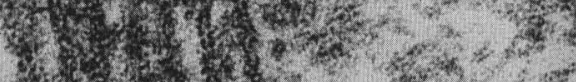
10.0.

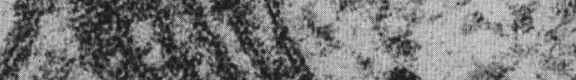

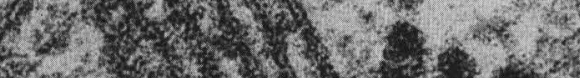

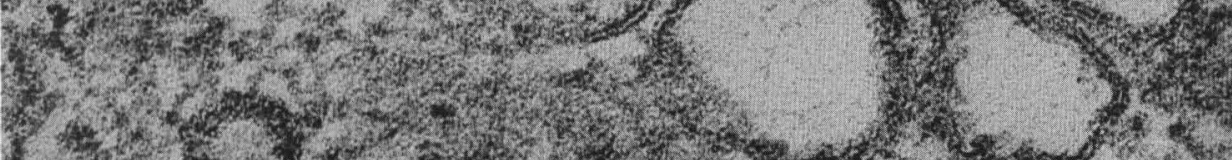

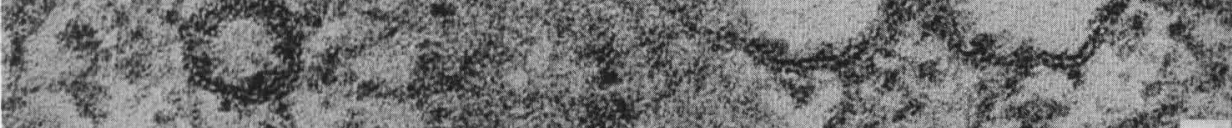

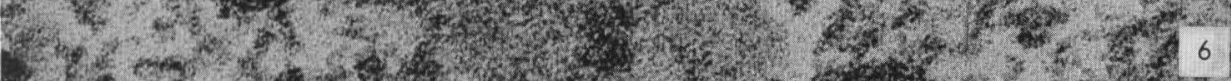


biomembranes (e.g., 22). It was estimated that radii of curvature of less than $150 \AA$ would be unstable assuming classic bimolecular leaflet arrangement according to the concept of Danielli and Davson (22). Since these "minipores" are hard to identify on the electron microscopic screen in both tangential and cross sections of cisternae, it is very probable that they have been simply overlooked in the previous electron microscopic work on cytomembranes. We believe that they occur generally in ER and dictyosomal cisternae. Moreover, we would also not exclude the possibility that their occurrence is not limited to associations of "homologous" membranes (ER, nuclear envelope, dictyosome cisterna, annulate lamellae), but that they may also occur with associations of "heterologous" membranes, such as the outer mitochondrial or plastidal double membranes. It remains an open question whether these "minipores" are stable structures or represent just snapshots of transitory local membrane breakage-fusion processes.

B. Additionally, the present study demonstrates that the "fenestrae" in dictyosomal cisternae are not simple interruptions, but can be associated with characteristic ultrastructural elements of a nonmembranous nature. The chief classes of such structures are: (i) Central dense granules or rods which show a high staining affinity to the uranyl and lead salts used in thin section electron microscopy. The frequent connections and associations of these central particles with the cytoplasmic ribosomes, as well as their behavior in a variety of cytochemical tests including the EDTA method of Bernhard (2), suggest that the central particles are of a ribonucleoprotein nature. (ii) Filamentous structures can also be recognized within the dictyosomal pores. Often these filaments appear to radiate from the central element and connect it to the pore walls.

It is obvious that these structural details represent a strong homology to the organization of the pore complexes of the nuclear envelope and the annulate lamellae. It therefore appears, e.g., that "central granules" are not structures unique to the nuclear and annulate lamellae pores. It should also be noted that the occurrence of central granules in the pores of ER and dictyosomal cisternae is not limited to the plant cells dealt with in the present study, but is very common in other plant and animal cells as well, including such diverse material as sea urchin oocytes, mammalian

FIG. 7. Tangential section to a dictyosomal No. 2 cisterna ( $D C 2$, lower left) and a No. 3 cisterna $(D C$ 3). Pores are significantly more numerous in DC 2 and are often marked by the central granule (arrows). Note thin threads connecting the central densities with the pore margin. $\times 108000$.

FIG. 8. A typical No. 1 dictyosome cisterna of a Haplopappus tissue culture cell. Here the pores are so numerous that the cisterna appears highly perforated. Note the central particles and the filamentous material within the pores (arrows). $\times 225000$.

Fig. 9. Same material as in Fig. 8. Dictyosome cisterna showing pores of variable size including larger ones, frequently with central granules (small arrow at the right), and smaller ones ("minipores", e.g., at the small arrows at the upper left) which are more clearly identified in the inset. The long arrows denote an intercisternal rod (for explanation see text). $\times 205000$; inset, $\times 400000$. 


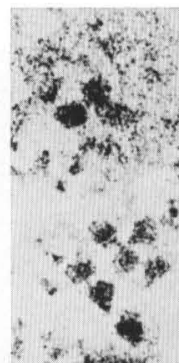

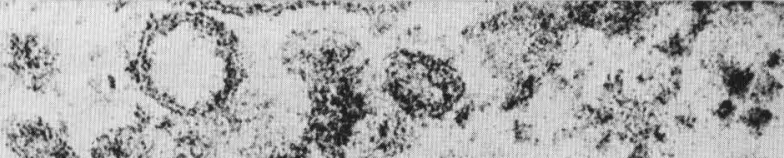

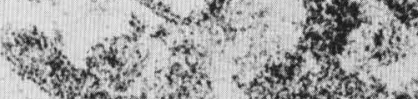

190.

(.) $3 x^{2}$ (3)

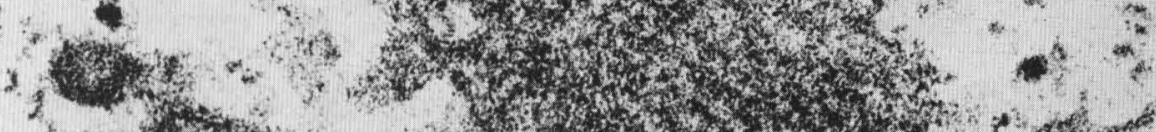

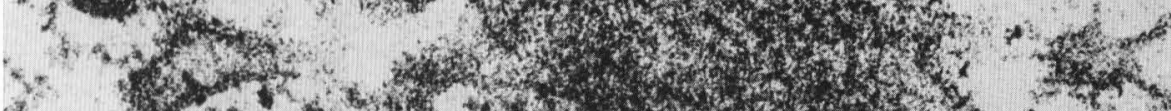

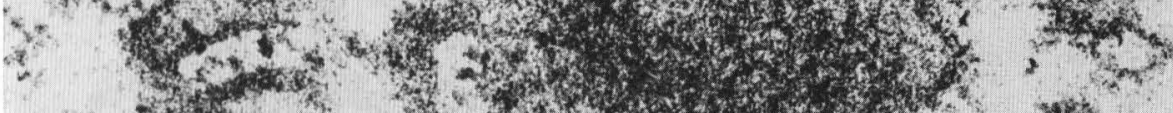

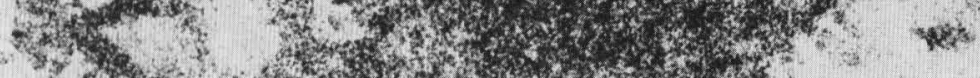

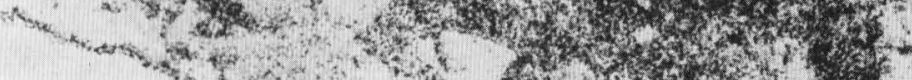

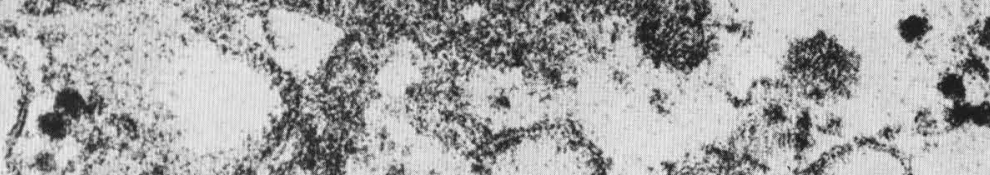
1.5.

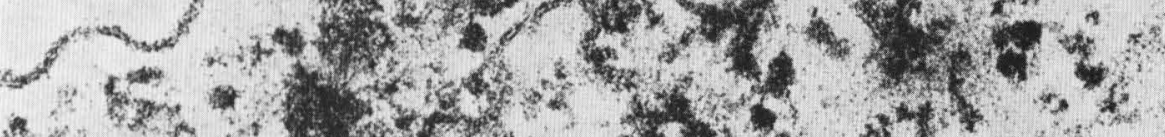

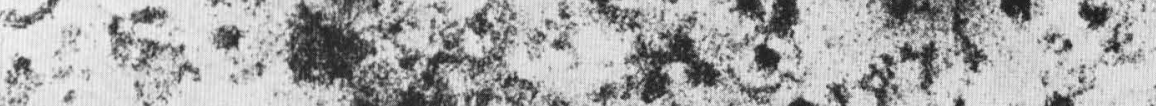

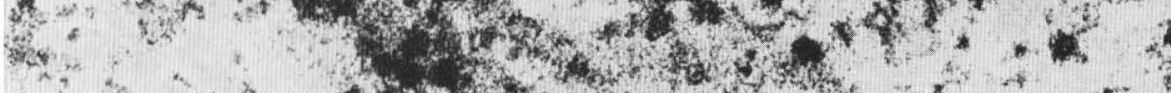

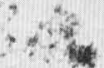

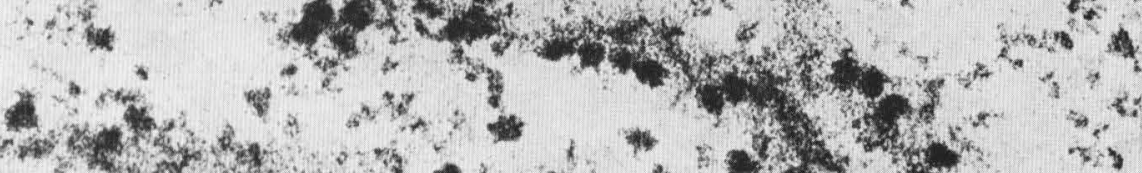

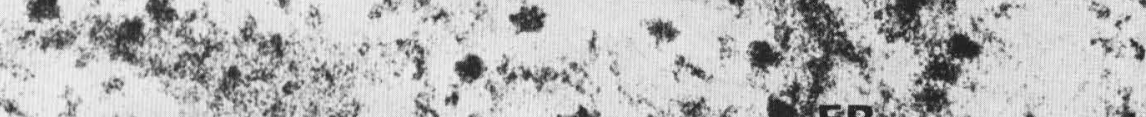

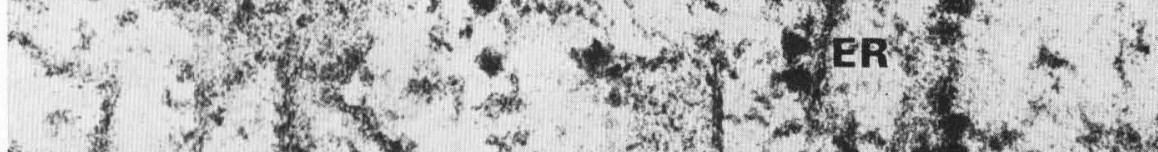

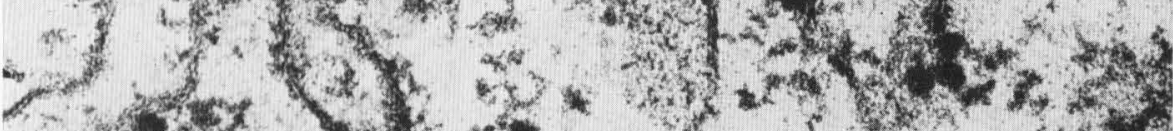

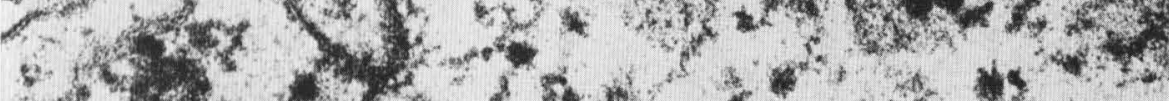

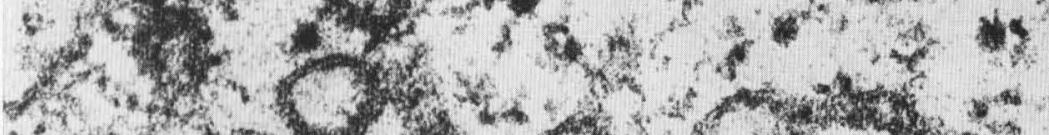

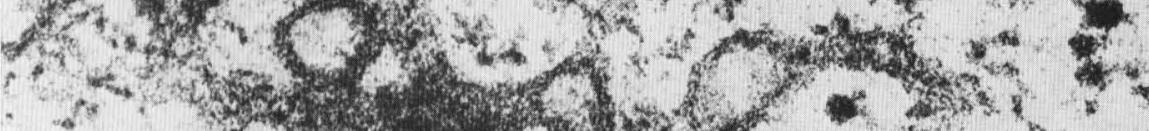

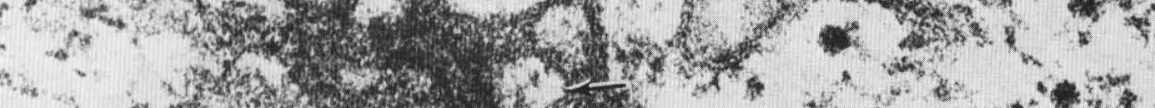

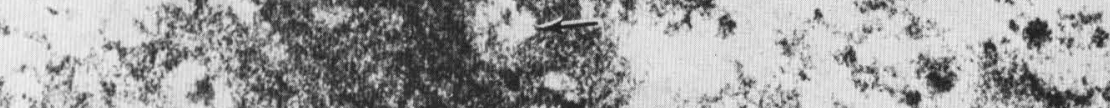

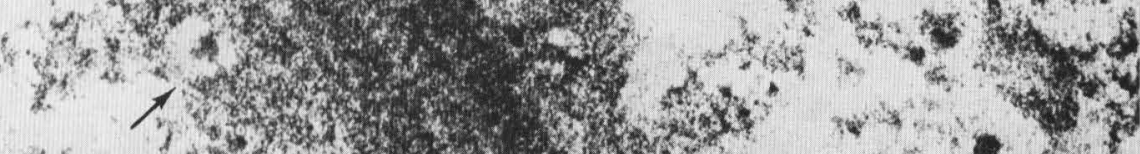

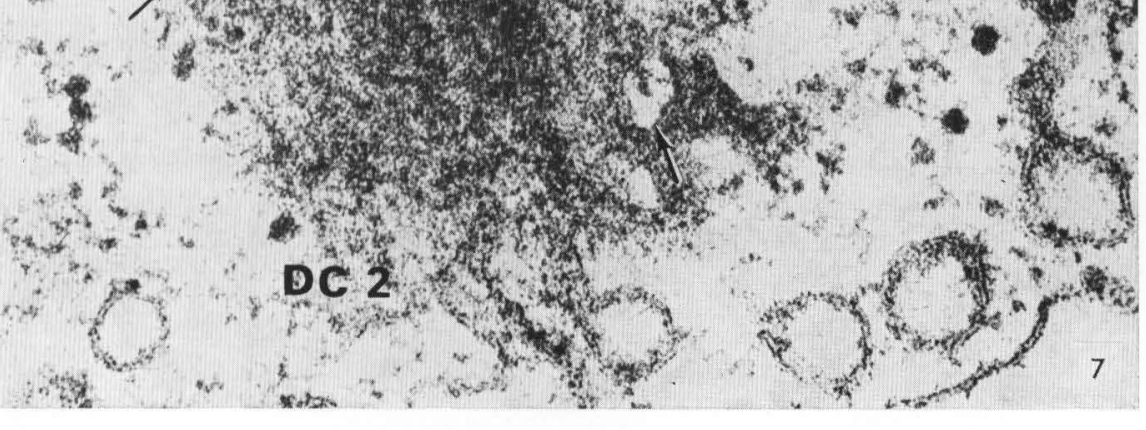




\section{W.t. (x)}

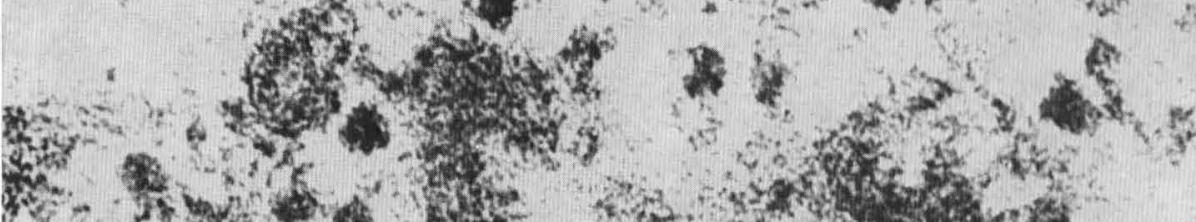

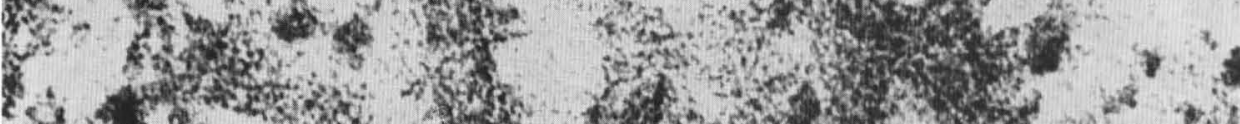
$y+x-2,1+2 x$

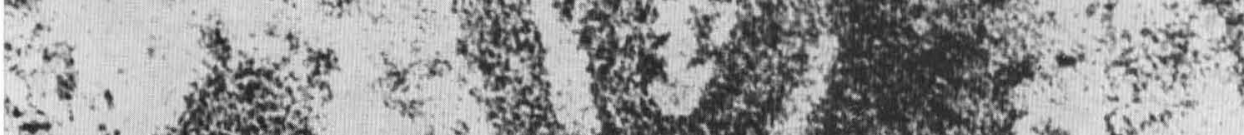

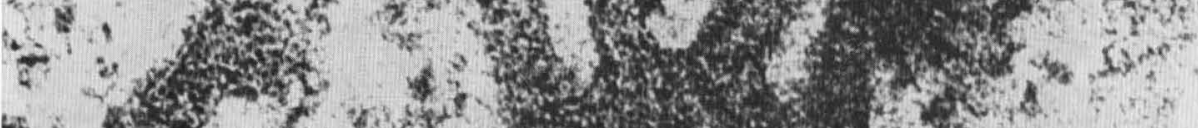

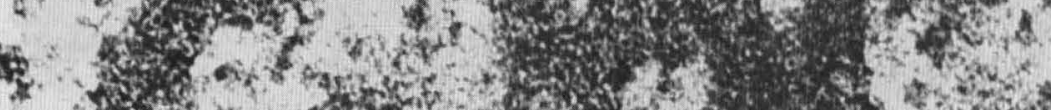

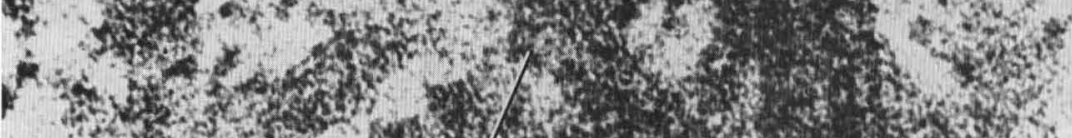

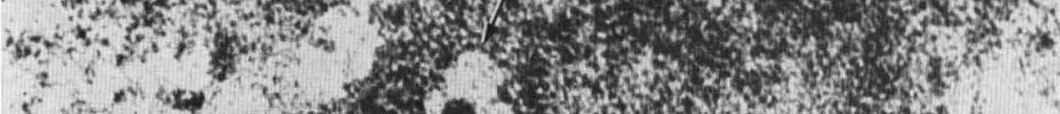

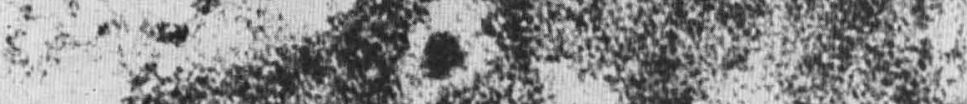

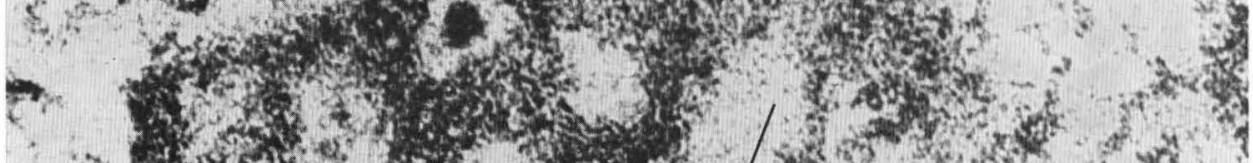

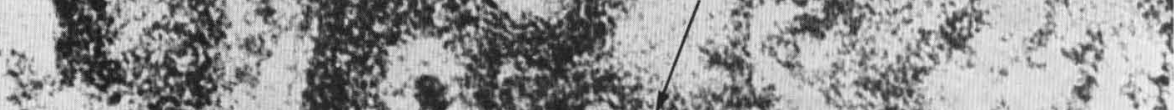

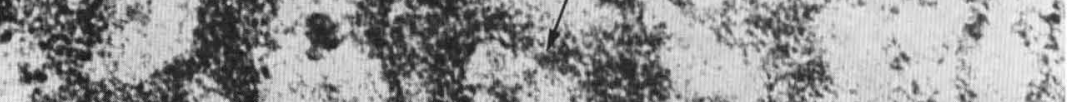

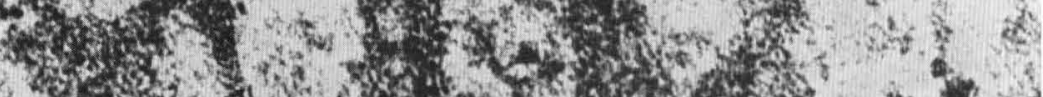

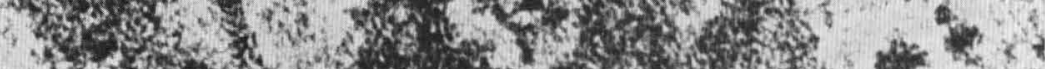

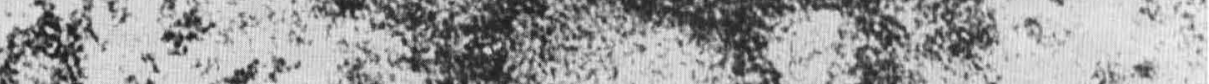

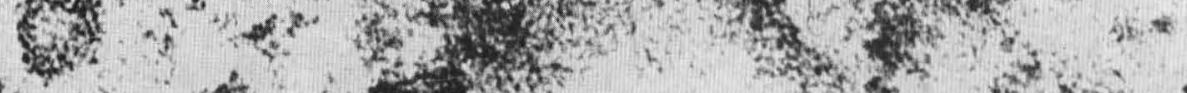

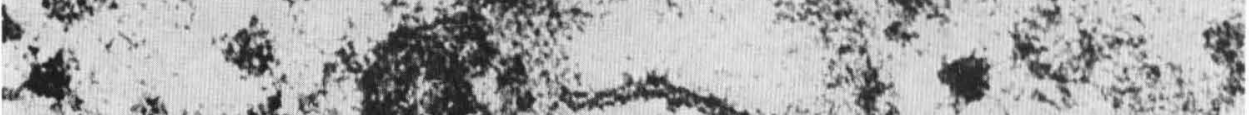

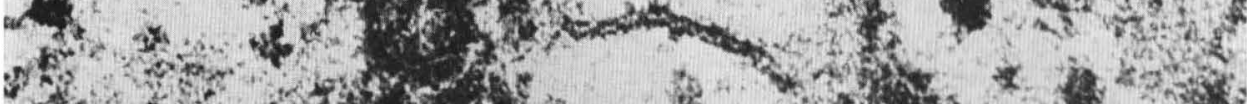

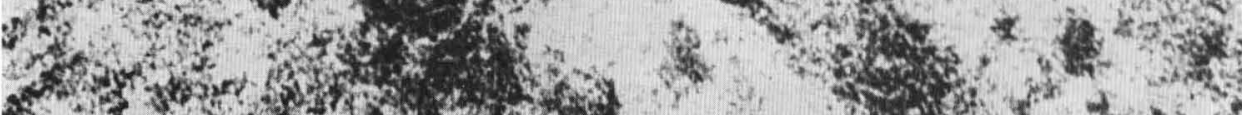

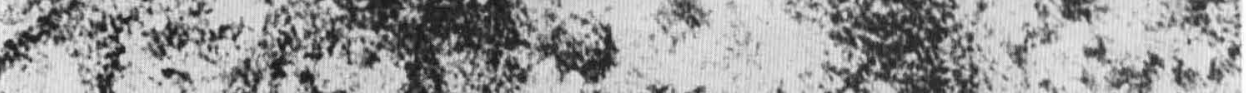

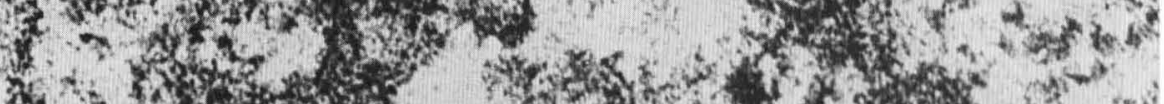

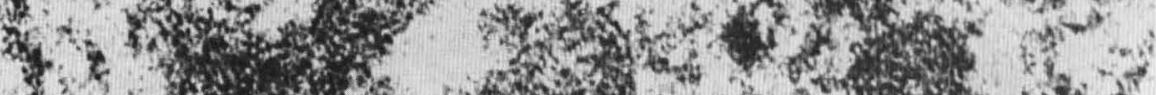

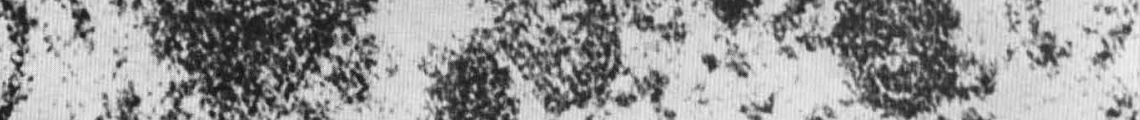

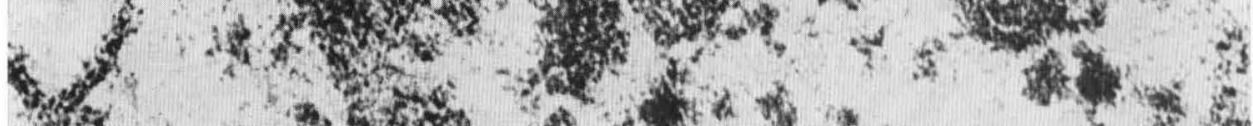

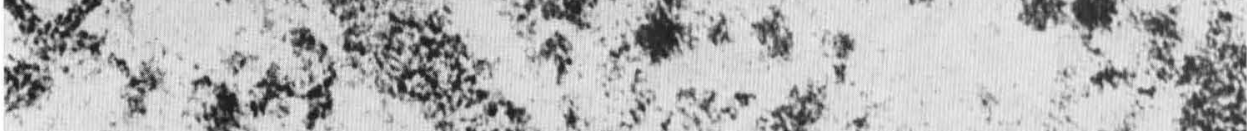

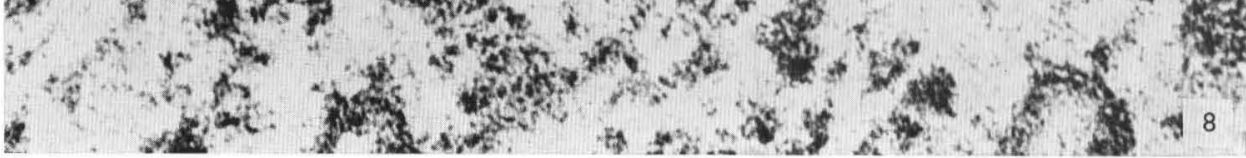




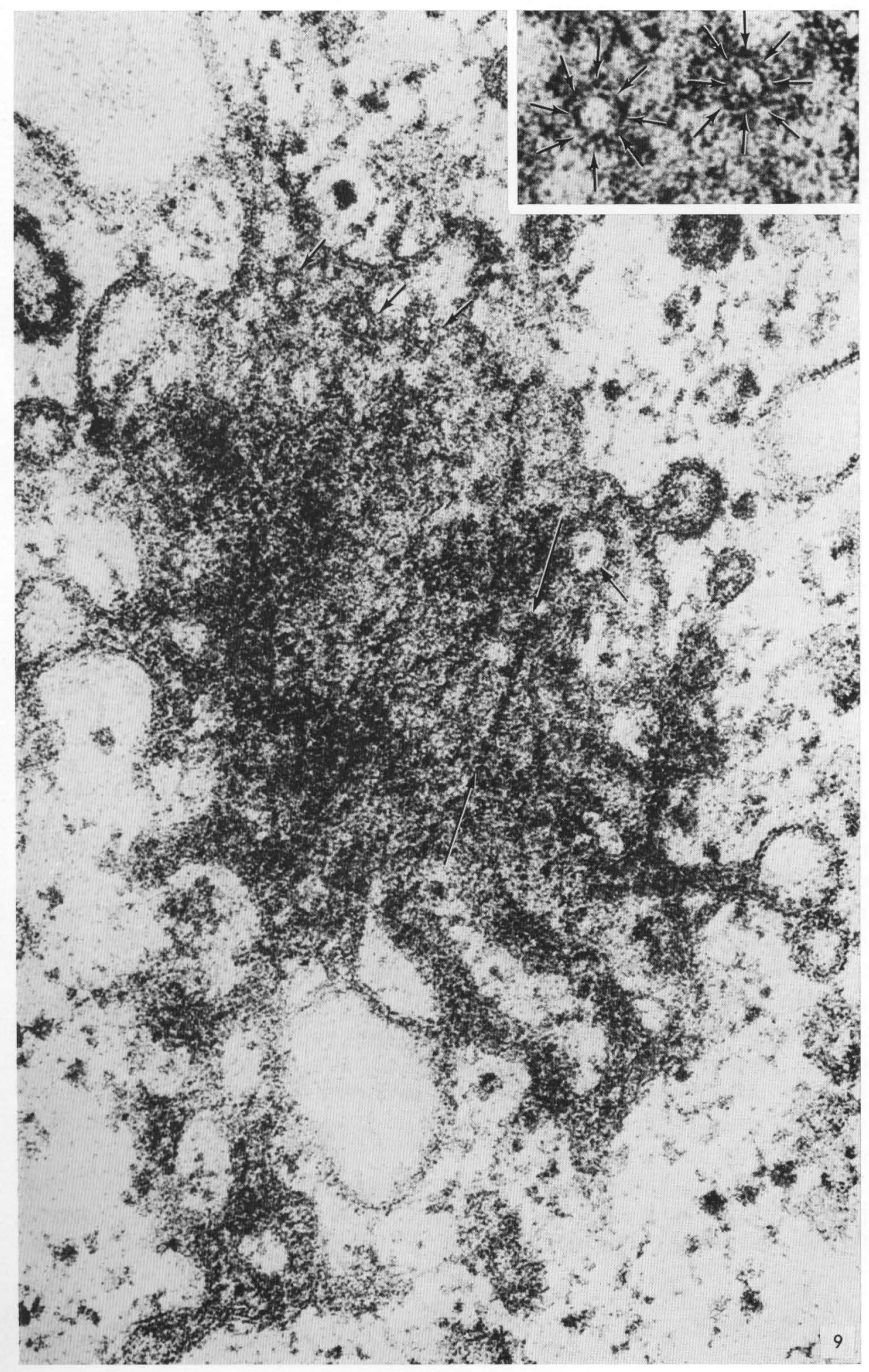




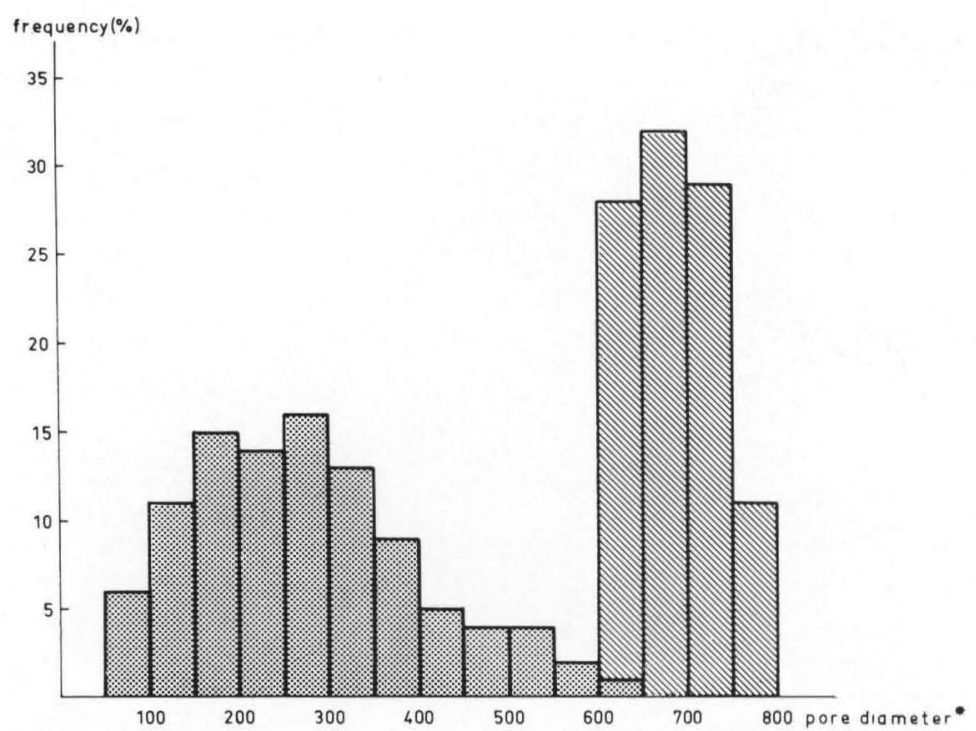

FIG. 10. Block diagram of the frequency of pore diameters in the dictyosomal (dotted blocks) and nuclear pores (striated blocks) in cultured Haplopappus cells. Frequency distributions do not considerably overlap. Nuclear pores are much more homogeneous in distribution. *Pore diameters determined by direct measurement of 200 Golgi pores and 200 nuclear pore complexes. The measurements were made across the inner pore diameters as shown in tangential sections and are expressed in Ångström units.

hepatocytes, pollen mother cells, and growing pollen cells of monocotyledons. Moreover, spot-checking of the literature has revealed in the illustrations of other authors further examples of central granules in dictyosomal and ER pores of various cell types $(3,4,16,17,23,27)$. It is also interesting to note in this connection that the abovedescribed elements of the dictyosomal pore interior remain attached to the cisternal membranes during isolation of sea urchin oocyte dictyosomes (Scheer, unpublished observation). From this we conclude that the presence of the filamentous and granular elements is a phenomenon common to pores of various cytomembrane systems and that their formation may have more to do with the processes of pore formation in general (compare the scheme in reference 6 ) than with being specifically indicative of the ribonucleoprotein particles migrating through the pore center (cf. 9, 26). The view that the central granules and the inner pore filaments form in the course of local membrane breakage and fusion events is further supported from their occurrence in the pores ("fenestrae") of the capillary endothelium $(11,17,20)$.

What, however, causes such pores to form with such a high frequency and at such preferential sites as the nuclear envelope and the forming face of the dictyosomes, for instance? A clue to this problem might perhaps come from the observation of the 
close spatial relationship of pores with ribonucleoprotein material. Situations like those shown, for instance, in Figs. 1, 4, and 5 suggest that the cytoplasmic ribosomes are involved in pore formation processes. Among the known chemical components of such ribonucleoprotein particles, neither the nucleic acid moiety nor the proteins associated are likely to induce local membrane lesions or porelike holes. A third component, however, which is consistently found in such particles in considerable quantities, the spermidine (e.g., 13, 24), would constitute a strong candidate for local membrane damaging through a disordering effect of its positive charges onto the negatively charged membrane surfaces (cf. also 1,14 ). However, experiments directed to examine the effect of such positively charged compounds on cytomembranes are required to check this hypothesis.

The authors are indebted to $\mathrm{Dr}$ R. Berezney for critically reading and discussing the manuscript and to Drs H. Falk and D. J. Morré (Purdue University, Lafayette, Indiana) for helpful discussions. We also thank Miss Sigrid Krien and Miss Marianne Winter for valuable technical assistance and $\mathrm{Mr} \mathrm{H}$. Fritsch for providing the Haplopappus culture material and Mr W. J. VanDerWoude (Purdue University) for gift of the Lilium pollen.

\section{REFERENCES}

1. Anderson, N. G. and Norris, C. B., Exp. Cell Res. 19, 605 (1960).

2. Bernhard, W., J. Ultrastruct. Res. 27, 250 (1969).

3. Claude, A., J. Cell Biol. 50, 1 (1971).

4. Esau, K. and Cronshaw, J., Can. J. Bot. 46, 877 (1968).

5. Franke, W. W., Z. Zellforsch. Mikrosk. Anat. 105, 405 (1970).

6. Franke, W. W., Eckert, W. A. and Krien, S., Z. Zellforsch. Mikrosk. Anat. 119, 577 (1971).

7. Franke, W. W., Herth, W., VanDerWoude, W. J. and Morré, D. J., Planta in press (1972).

8. Franke, W. W., Kartenbeck, J., Zentgraf, H. W., Scheer, U. and Falk, H., J. Cell Biol. 51, 881 (1971).

9. Franke, W. W. and Scheer, U., J. Ultrastruct. Res. 30, 317 (1970).

10. Franke, W. W., Scheer, U. and Fritsch, H., J. Cell Biol. in press (1972).

11. Friederici, H. H. R., J. Ultrastruct. Res. 27, 373 (1969).

12. Gall, J. G., Protoplasmatologia 5, 4 (1964).

13. Gfeller, E. and Russell, D. H., Z. Zellforsch. Mikrosk. Anat. 120, 321 (1971).

14. HanCoCk, R. and Ryser, H. J. P., Nature (London) 213, 701 (1967).

15. Kessel, R. G., J. Ultrastruct. Res., Suppl. 10, 1 (1968).

16. — ibid. 22, 63 (1968).

17. Maul, G. G., J. Ultrastruct. Res. 30, 368 (1970).

18. — ibid. 37, 232 (1971).

19. Mollenhauer, H. H. and Morré, D. J., Annu. Rev. Plant Physiol. 17, 27 (1966).

20. Palade, G. E. and Bruns, R. R., J. Cell Biol. 37, 633 (1968).

21. Pollister, A. W., Gettner, M. and Ward, R., Science 120, 789 (1954). 
22. Robertson, J. D., in Locke, M. (Ed.), Cellular Membranes in Development, p. 1. Academic Press, New York, 1964.

23. Schnepf, E., Planta 79, 22 (1968).

24. Spirin, A. S. and Gavrilova, L. P., The Ribosome. Springer-Verlag, Berlin, 1969.

25. Stevens, B. J. and André, J., in Lima-de-Faria, A. (Ed.), Handbook of Molecular Cytology, p. 837. North-Holland Publ., Amsterdam, 1969.

26. Stevens, B. J. and Swift, H., J. Cell Biol. 31, 55 (1966).

27. Stockem, W., Histochemie 18, 217 (1969).

28. Watson, M. L., J. Biophys. Biochem. Cytol. 6, 147 (1959). 